University of Nebraska - Lincoln

DigitalCommons@University of Nebraska - Lincoln

Faculty Publications: Materials Research

Science and Engineering Center

Materials Research Science and Engineering

Center

July 2004

\title{
Nanostructure and Magnetic Properties of FePt :C Cluster Films
}

Yinfan Xu

University of Nebraska - Lincoln, yxu2@unl.edu

M. L. Yan

University of Nebraska - Lincoln

David J. Sellmyer

University of Nebraska-Lincoln, dsellmyer@unl.edu

Follow this and additional works at: https://digitalcommons.unl.edu/mrsecfacpubs

Part of the Materials Science and Engineering Commons

Xu, Yinfan; Yan, M. L.; and Sellmyer, David J., "Nanostructure and Magnetic Properties of FePt :C Cluster Films" (2004). Faculty Publications: Materials Research Science and Engineering Center. 20.

https://digitalcommons.unl.edu/mrsecfacpubs/20

This Article is brought to you for free and open access by the Materials Research Science and Engineering Center at DigitalCommons@University of Nebraska - Lincoln. It has been accepted for inclusion in Faculty Publications:

Materials Research Science and Engineering Center by an authorized administrator of DigitalCommons@University of Nebraska - Lincoln. 


\title{
Nanostructure and Magnetic Properties of FePt: C Cluster Films
}

\author{
Yingfan Xu, M. L. Yan, and D. J. Sellmyer, Member, IEEE
}

\begin{abstract}
Magnetic properties and nanostructure of FePt : C cluster-deposited films with $\mathrm{C}$ volume fraction of $7 \%, 14 \%, 33 \%$, and $45 \%$ have been studied. As-deposited FePt : C films were prepared by a multilayer method in which FePt layers were deposited from a cluster source employing a gas-aggregation technique and $\mathrm{C}$ layers from a normal sputtering gun. In the as-deposited films, FePt clusters with fec structure are embedded in the $\mathrm{C}$ matrix. The high anisotropy $\mathrm{FePt} \mathrm{L1}_{0}$ cluster structure was realized in the films via post-deposition annealing and the nanostructure of the films was observed by high-resolution transmission electron microscope (TEM). The results for a film with 45 vol. \% $\mathrm{C}$ showed that $\mathrm{FePt}$ clusters are well separated by $\mathrm{C}$ matrix and the cluster diameter is about $4.5 \mathrm{~nm}$. The coercivity increases with increase of annealing temperature; coercivities larger than $9 \mathrm{kOe}$ were achieved in the films after annealing at a temperature of $700{ }^{\circ} \mathrm{C}$ and above. Magnetization reversal of the films was studied by moment-decay measurements and the data were fitted with the Sharrock formula. For the film with 45 vol. $\% \mathrm{C}$ annealed at $625{ }^{\circ} \mathrm{C}$, the thermal stability factor $K_{u} V^{*} / k_{B}, T$ activation volume $V^{*}$, and anisotropy constant $K_{u}$ are $231,0.83 \times 10^{-18} \mathrm{~cm}^{3}$ and $1.2 \times 10^{7} \mathrm{erg} / \mathrm{cm}^{3}$, respectively.
\end{abstract}

Index Terms-FePt, high anisotropy, $\mathrm{L1}_{0}$ structure, nanocluster, thermal stability.

\section{INTRODUCTION}

$\mathbf{F}$ e FePt nanoparticles with the high-anisotropy $\mathrm{L} 1_{0}$ ordered phase have significant potential for extremely high-density magnetic recording (EHDR) defined as approaching an areal density of $1 \mathrm{~Tb} / \mathrm{in}^{2}$. This follows from the favorable properties of FePt including its magnetic crystalline anisotropy constant (about $7 \times 10^{7} \mathrm{erg} / \mathrm{cm}^{3}$ ) and good chemical stability [1], [2] In order to improve the signal-to-noise ratio, the medium for EHDR requires magnetically decoupled or weakly coupled particles having sizes below $10 \mathrm{~nm}$ with an extremely uniform size distribution and thermal stability at room temperature [3]. We have prepared FePt and CoPt nanoclusters with small cluster size (ranging from 3 to $6 \mathrm{~nm}$ in diameter) by using a gas-aggregation technique, in which magnetron sputtering is employed in the cluster source [4], [5]. Fig. 1 shows an example of highresolution TEM image of FePt nanoclusters with narrow size distribution (standard deviation $\sigma / d \sim 0.1$, where $d$ is mean diameter).

In this study, FePt: $\mathrm{C}$ nanocluster films with different $\mathrm{C}$ volume fraction have been prepared. Carbon is used as matrix

Manuscript received October 12, 2003. This work was supported by INSIC, NSF-MRSEC, NIST, ARO, Keck Foundation, and NRI.

The authors are with the Department of Physics and Astronomy and Center for Materials Research and Analysis, University of Nebraska, Lincoln, NE 68588 USA (e-mail: yxu2@unl.edu).

Digital Object Identifier 10.1109/TMAG.2004.832496

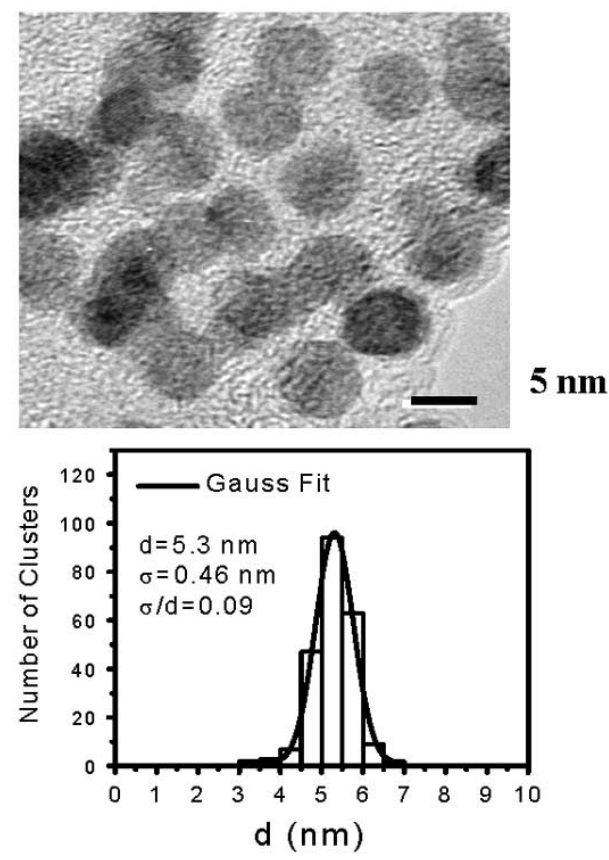

Fig. 1. TEM image of FePt nanoclusters deposited at a power of $200 \mathrm{~W}$. Shown below is corresponding cluster size distribution.

for the purpose of isolating the FePt clusters to decrease the exchange interaction, and to reduce the cluster growth during high-temperature annealing.

\section{EXPERIMENT}

FePt:C nanocluster films were prepared with a multilayer method in which FePt cluster layers (produced by the gas-aggregation technique) and $\mathrm{C}$ layers (produced by a normal sputtering gun) were alternately deposited onto a $\mathrm{Si}$ substrate. The initial nominal dimensions of the multilayer are given by $[\operatorname{FePt}(x \mathrm{~nm}) / \mathrm{C}(y \mathrm{~nm})]_{\times 6}$, where $x \approx 1 \mathrm{~nm}$ and $0.075 \leq y \leq 0.825 \mathrm{~nm}$, corresponding to $\mathrm{C}$ volume fraction changing from $7 \%$ to $45 \%$. Since the FePt clusters are approximately spherical with $d \sim 4.5 \mathrm{~nm}$, prepared with a power of $100 \mathrm{~W}, x \approx 1 \mathrm{~nm}$ implies only a partial occupancy of the cluster layers. The high-anisotropy $\mathrm{FePt} \mathrm{L}_{0}$ structure was obtained with post-deposition annealing using a rapid-thermal-annealing oven. Crystal structure and nanostructure of the FePt: C films were examined with a Rigaku X-ray diffractometer (XRD) using $\mathrm{CuK}_{\alpha}$ radiation and a JEOL 2010 transmission electron microscope (TEM). Magnetic properties and moment-decay measurements were carried out with an alternative gradient force magnetometer (AGFM). 


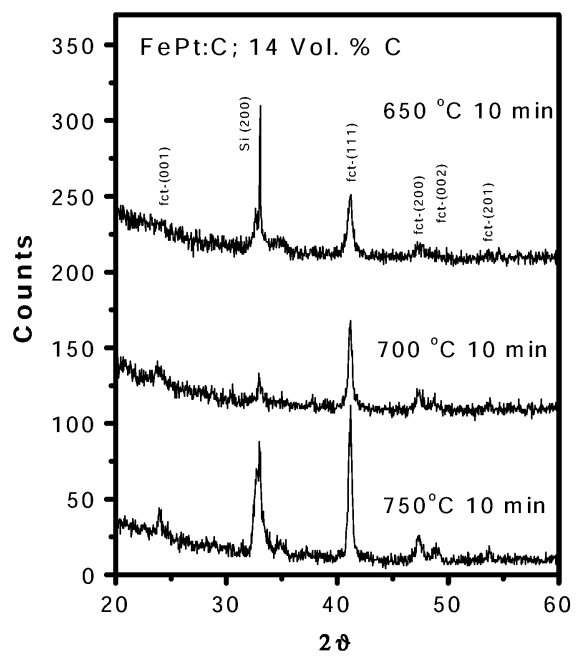

Fig. 2. XRD $(\theta-2 \theta)$ scans of FePt : C cluster films with 14 vol. \% C annealed at different temperature for $10 \mathrm{~min}$.

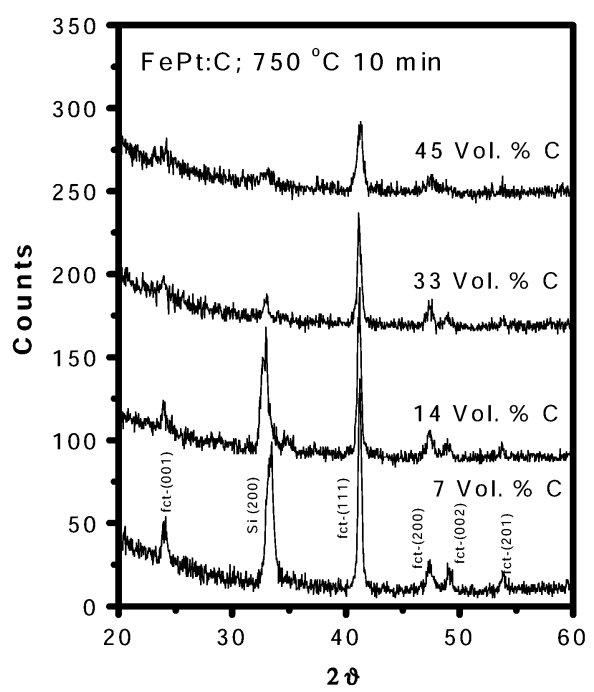

Fig. 3. XRD $(\theta-2 \theta)$ scans of FePt : C films with different $\mathrm{C}$ volume fraction annealed at $750{ }^{\circ} \mathrm{C}$ for $10 \mathrm{~min}$.

\section{RESUlTS AND DisCUSSION}

XRD measurements confirmed the ordering of the $\mathrm{L} 1_{0}$ structure. Fig. 2 shows the XRD $(\theta-2 \theta)$ scans of FePt: C cluster films with 14 vol. $\% \mathrm{C}$ annealed at $650{ }^{\circ} \mathrm{C}, 700^{\circ} \mathrm{C}$, and $750{ }^{\circ} \mathrm{C}$ for $10 \mathrm{~min}$, respectively. The intensity of the $\mathrm{L} 1_{0}$-structure peaks increases with annealing temperature, indicating that the $\mathrm{L} 1_{0}$ ordering started to develop at $650^{\circ} \mathrm{C}$, and trended toward a completion at temperatures higher than $700^{\circ} \mathrm{C}$. The peak width decreased clearly after annealing at $750{ }^{\circ} \mathrm{C}$, suggesting the cluster growth in the films annealed at high temperature. Fig. 3 shows XRD spectra of the $\mathrm{FePt}$ : C cluster films with different $\mathrm{C}$ volume fraction annealed at $750{ }^{\circ} \mathrm{C}$ for $10 \mathrm{~min}$. The intensity of the $\mathrm{L} 1_{0}$-structure peaks decreases with increase of $\mathrm{C}$ volume fraction, while the peak width increases with the increase of $\mathrm{C}$ content, suggesting that increase of carbon content reduced the FePt cluster growth.

Fig. 4 shows the dependence of in-plane and perpendicular coercivities of FePt : C films with 45 vol. \% $\mathrm{C}$ on the annealing

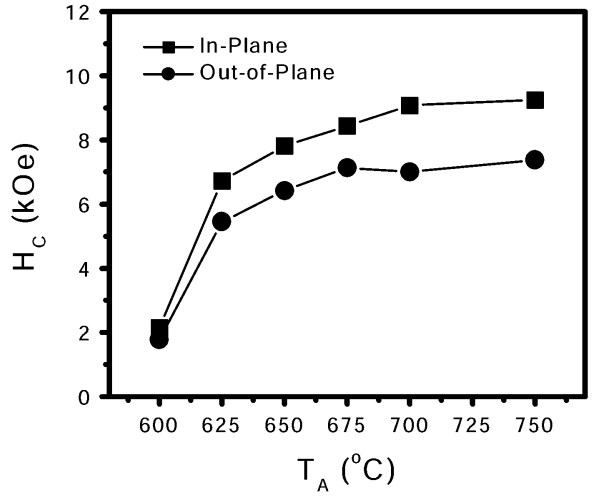

Fig. 4. Effect of annealing temperature on in-plane and out-of-plane coercivities of FePt : C cluster films with 45 vol. \% C. Annealing time: 10 min.

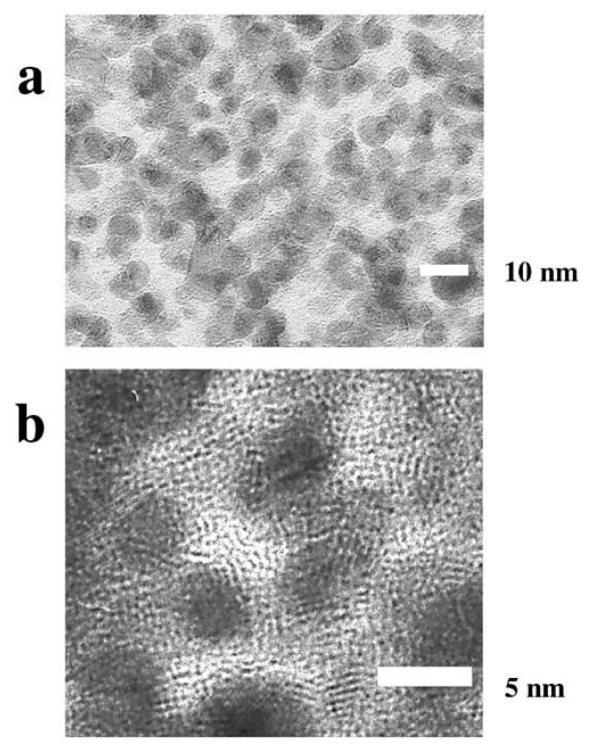

Fig. 5. (a) TEM bright field image of FePt: $\mathrm{C}$ cluster film with 45 vol. $\% \mathrm{C}$ and (b) the high-resolution image. The film was annealed at $650^{\circ} \mathrm{C}$ for $10 \mathrm{~min}$.

temperature $T_{A}$. Both in-plane ( $H / /$ film plane) and out-ofplane $(H \perp$ film plane) coercivities increased with increase of annealing temperature. The coercivities increased rapidly with $T_{A}$ between $600{ }^{\circ} \mathrm{C}$ and $650{ }^{\circ} \mathrm{C}$, then increased slowly with $T_{A}$ above $650{ }^{\circ} \mathrm{C}$. The in-plane coercivity is about 2 kOe higher than the out-of-plane coercivity. The in-plane coercivity larger than $9 \mathrm{kOe}$ was achieved in the films after annealing at a temperature of $700{ }^{\circ} \mathrm{C}$ and above. Since the maximum magnetic field applied to the sample was $13 \mathrm{kOe}$ during AGFM measurement, it is possible that magnetization was not saturated, which might result in smaller measured value of coercivity for films annealed at higher temperature.

Fig. 5 shows the TEM plan-view images for the FePt:C film with 45 vol. $\% \mathrm{C}$ annealed at $650{ }^{\circ} \mathrm{C}$ for $10 \mathrm{~min}$. $\mathrm{FePt}$ clusters are embedded in $\mathrm{C}$ matrix. Shown in Fig. 5(b) is the high-resolution TEM image. It shows that single FePt clusters with diameter about $4.5 \mathrm{~nm}$ were well separated by amorphous $\mathrm{C}$ matrix; the cluster growth during high temperature annealing has been remarkably reduced with addition of higher volume fraction of $\mathrm{C}$. 


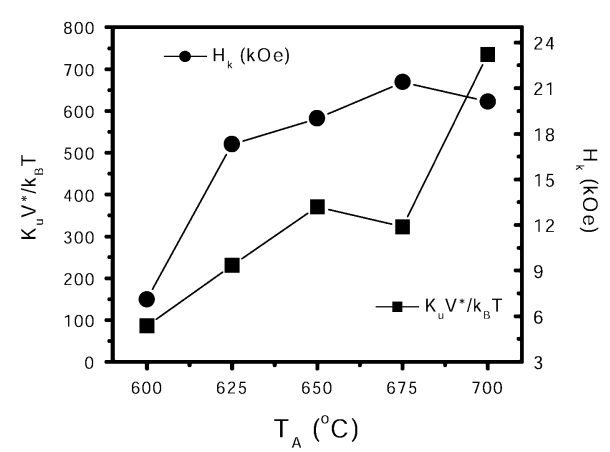

Fig. 6. Effect of annealing temperature on thermal stability and magnetic anisotropy field of $\mathrm{FePt}$ : C cluster films with 45 vol. \% C. Annealing time: $10 \mathrm{~min}$.

As grain size gets smaller and smaller with increased recording areal density, the magnetic moment in grain may reverse spontaneously via thermal activation. Therefore, understanding the magnetization reversal behavior of media is of essential importance to control and design new media with desired properties and good thermal stability. We carried out a set of moment decay measurements with the AGFM for FePt:C films with 45 vol. \% C. The data were fitted with Sharrock formula [6] and the thermal stability factor and anisotropy constant were extracted from the fitting parameters. The detailed experiment and fitting procedures can be found in [7]. Fig. 6 shows the annealing effect on the thermal stability factor $K_{u} V^{*} / k_{B} T$ and anisotropy field $H_{k}$ for the FePt:C films with 45 vol. \% C. $H_{k}$ was calculated from $H_{0}=0.48 H_{k}$, assuming that the clusters were decoupled by $\mathrm{C}$ isolation. $H_{0}$ was obtained from the Sharrock fitting parameter. $H_{k}$ increases rapidly with annealing temperature $T_{A}$ between $600{ }^{\circ} \mathrm{C}$ and $625^{\circ} \mathrm{C}$, then increases slowly and to saturation for $T_{A}>625{ }^{\circ} \mathrm{C} . K_{u} V^{*} / k_{B} T$ increases linearly with $T_{A}$ except for the point at $675{ }^{\circ} \mathrm{C}$ that might be caused by either experimental error or $V^{*}$ being unusually small. $M_{s}$ decreases with the increase of $T_{A}$, e.g., $M_{s}$ is about $654 \mathrm{emu} / \mathrm{cm}^{3}$ for $T_{A}=650{ }^{\circ} \mathrm{C}$ and $621 \mathrm{emu} / \mathrm{cm}^{3}$ for $700{ }^{\circ} \mathrm{C}$. Since $K_{u}$ would be constant after the completion of $\mathrm{L}_{0}$ ordering, the further increase of $K_{u} V^{*} / k_{B} T$ with $T_{A}$ is mainly due to the increase of $V^{*}$. As shown in Fig. 7, $K_{u}$ is about $1.2 \times 10^{7} \mathrm{erg} / \mathrm{cm}^{3}$ for $T_{A}>625^{\circ} \mathrm{C} ; V^{*}$ increases slowly initially and then increases more rapidly with $T_{A}$, which results in the quasi-linear increase of $K_{u} V^{*} / k_{B} \mathrm{~T}$.

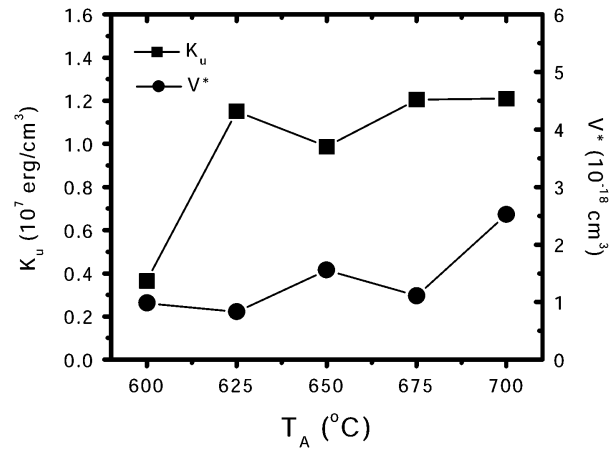

Fig. 7. Effect of annealing temperature on magnetic anisotropy constant and activation volume of FePt : C cluster films with 45 vol. \% C.

\section{CONCLUSION}

$\mathrm{L} 1_{0}$ structure ordered FePt: $\mathrm{C}$ nanocluster films have been prepared by the cluster-deposition technique and subsequent thermal annealing. Magnetic and nanostructural properties of the cluster films have been systematically investigated. The thermal stability factor $K_{u} V^{*} / k_{B} T$, activation volume $V^{*}$, and anisotropy constant $K_{u}$ are obtained from the moment-decay measurements and Sharrock formula fitting. The FePt nanoclusters studied are thermally stable, have a narrow size distribution and controllable coercivities. Their properties are similar to those required for magnetic recording at extremely high densities, i.e., approaching an areal density of $1 \mathrm{~Tb} / \mathrm{in}^{2}$ [3]. For practical application, the cluster orientation and film roughness must be further investigated and controlled.

\section{REFERENCES}

[1] S. Sun, C. B. Murray, D. Weller, L. Folks, and A. Moser, "Monodisperse FePt nanoparticles and ferromagnetic FePt nanocrystal superlattices," Science, vol. 287, pp. 1989-1992, 2000.

[2] D. J. Sellmyer, C. P. Luo, M. L. Yan, and Y. Liu, "High-anisotropy nanocomposite films for magnetic recording," IEEE Trans. Magn., vol. 37, pp. 1286-1291, July 2001.

[3] R. Wood, "The feasibility of magnetic recording at 1 terabit per square inch," IEEE Trans. Magn., vol. 36, pp. 36-42, Jan. 2000.

[4] Y. Xu, Z. G. Sun, Y. Qiang, and D. J. Sellmyer, "Magnetic properties of $\mathrm{L1}_{0}$ FePt and FePt: Ag nanocluster films," J. Appl. Phys., vol. 93, pp. 8289-8291, 2003

[5] - "Preparation and magnetic properties of CoPt and CoPt : Ag nanocluster films," J. Magn. Magn. Mater, vol. 266, pp. 164-170, 2003.

[6] M. P. Sharrock, "Time dependence of switching fields in magnetic recording media," J. Appl. Phys., vol. 76, pp. 6413-6418, 1994.

[7] Y. Xu, Z. S. Shan, J. P. Wang, and C. T. Chong, "Magnetic and reversal properties of HCP-CoCrPt : C granular films with CrTi underlayer," $J$. Magn. Magn. Mater, vol. 232, pp. 103-113, 2001. 